\title{
EROSÃO REMONTANTE EM CABECEIRAS DE DRENAGEM E AÇÃO ANTRÓPICA: O CASO DO CÓRREGO SANTA CRUZINHA, AFLUENTE DO RIO SANTO ANASTÁCIO - OESTE DO ESTADO DE SÃO PAULO
}

\author{
Cristiano Capellani Quaresma ${ }^{(a)}$, Archimedes Perez Filho ${ }^{(\mathrm{b})}$, Raul Reis Amorim ${ }^{(\mathrm{c})}$, Maurício \\ Lamano Ferreira ${ }^{(d)}$
}

\author{
(a) PPGCIS, UNINOVE, quaresmacc@ uni9.pro.br \\ (b) Depto. Geografia/IG - Unicamp, archi@ige.unicamp.br \\ (c) Depto. Geografia/IG, Unicamp, raul_reis@ige.unicamp.br \\ (d) PPGCIS, UNINOVE, mauriciolamano@uni9.pro.br
}

Eixo: Uso e ocupação das terras e legislação ambiental

\begin{abstract}
Resumo
A erosão dos solos impacta a sustentabilidade das terras. Assim, estudos que definam o tipo de erosão existente e a sua evolução tornam-se indispensável à políticas públicas ligadas à conservação e à recuperação de áreas degradadas. Neste sentido, o presente trabalho objetivou identificar a ocorrência de erosão remontante em canais de primeira ordem do Córrego Santa Cruzinha, afluente do Rio Santo Anastácio e localizado no oeste do estado de São Paulo. Para tanto, realizou-se uma análise comparativa entre a rede de drenagem de 1962 e de 2010, com base em fotointerpretação e em análise morfométrica, fundamentada nos índices Dd (densidade de drenagem) e Dh (densidade hidrográfica). Os resultados demonstraram a existência de erosão remontante, indicando reativação da rede de drenagem. Espera-se que o presente estudo contribua para com futuros trabalhos e para com políticas públicas que visem a gestão de áreas degradadas e do ordenamento do uso e ocupação das terras.
\end{abstract}

Palavras chave: Erosão dos Solos; Rede de drenagem; Gestão de áreas degradadas.

\section{Introdução}

A erosão dos solos se constitui em um grande problema de sustentabilidade, haja vista que impacta as esferas econômica, social e ambiental.

Na esfera econômica exige maiores investimentos em insumos destinados à correção nutricional dos solos em razão da redução da fertilidade das terras agricultáveis. Além disso, reflete diretamente na produtividade da terra, impactando o PIB nacional, que depende fortemente do setor agropastoril.

Com relação à esfera social, a perda de solos agricultáveis trata-se de uma das principais causas de escassez de alimento em diversas áreas do planeta. As consequências negativas desta perda certamente recaem com maior intensidade sobre a população mais carente. 
$\mathrm{Na}$ esfera ambiental, a erosão impacta todo o ecossistema terrestre, tendo em vista que degrada o meio de desenvolvimento das plantas, as quais se constituem na base de toda cadeia alimentar. Também afeta os ecossistemas aquáticos devido ao assoreamento de canais fluviais, prejudicando a qualidade das águas e a vida dos seres que nela vivem, ou que dela dependem. Além disso, o assoreamento também prejudica a sociedade, tendo em vista que impõe obstáculos aos sistemas de coleta e abastecimento de água em áreas rurais e urbanas.

Tais impactos podem ser verificados claramente nas principais bacias hidrográficas do oeste do estado de São Paulo, dentre as quais se destaca a bacia do Córrego Santa Cruzinha, afluente do baixo curso do Rio Santo Anastácio.

Diante desses problemas, grande ônus tem sido imputado à sociedade e ao poder público, os quais se veem obrigados a realizar grandes investimentos para fins de controle e mitigação dos processos erosivos existentes.

Isso revela a importância de estudos que visam entender a gênese e a dinâmica dos processos erosivos desenvolvidos na região, especialmente para o poder público que, em muitos casos, carece de trabalhos técnicos que auxiliam na tomada de decisões em relação ao adequado enfrentamento do problema.

A definição do tipo de erosão e a caracterização de sua evolução são elementos indispensáveis à escolha das práticas de conservação e recuperação adequadas ao problema.

Grande parte dos estudos existentes sobre erosão de solos em bacias hidrográficas do Oeste do estado de São Paulo se concentram nas incisões lineares desenvolvidas ao longo das vertentes. Outros têm apontado para a intensa erosão exercida nos canais fluviais, os quais indicam retomada erosiva remontante, com nítido aprofundamento das calhas fluviais e aumento do número e comprimento dos canais de primeira ordem.

Na tentativa de contribuir com tais estudos, o presente trabalho buscou identificar a ocorrência de erosão remontante em canais de primeira ordem do Córrego Santa Cruzinha, afluente do Rio Santo Anastácio e localizado no oeste do estado de São Paulo.

Espera-se que os resultados apresentados permitam uma melhor visualização do estado erosivo da bacia em estudo, possibilitando subsidiar futuros trabalhos, bem como políticas públicas e ações privadas que visem controlar a perda de solos e os processos de assoreamento de ocorrência generalizada na região. 


\section{Referencial Teórico}

\subsection{O problema da erosão dos solos}

O problema da erosão é antigo na história da humanidade, aparecendo desde as grandes civilizações. Além disso, encontra-se difundido por várias regiões do planeta e sua aceleração tem ocorrido ao longo dos anos pelas práticas erradas de uso e ocupação das terras (GUERRA, 1999).

Segundo Press et al. (2006), a erosão trata-se do conjunto de processos que desagregam e transportam solo e rochas morro abaixo ou na direção do vento, depositando-o em outro lugar. Deste modo, tal processo, ao lado da tectônica, do vulcanismo e do intemperismo, é considerado pelos autores como sendo importante no ciclo das rochas, na modelagem da superfície terrestre, na transformação de rochas em sedimentos e na formação dos solos.

Desse modo, a erosão trata-se de um processo natural, entretanto, o uso e ocupação desenfreados das terras por parte da sociedade têm rompido o equilíbrio natural das mesmas, especialmente pela remoção da cobertura vegetal natural, gerando assim processos erosivos mais intensos e acelerados.

Entende-se por erosão acelerada, conforme definição apontada por Quaresma (2012), o desprendimento e o arraste acelerado das partículas do solo por ação da água e/ou de outros agentes de transporte, porém desencadeados pela interferência antrópica no funcionamento do sistema natural, constituindo-se na principal causa de depauperamento acelerado das terras.

No Brasil, apesar de se tratar de um país privilegiado em terras agricultáveis, as práticas inadequadas de uso e ocupação agropastoris facilitam e aceleram a erosão hídrica, provocando o desgaste dos solos e a redução de sua fertilidade e produtividade ao longo dos anos (MARQUES, 1966).

Além dos efeitos sobre a capacidade produtiva dos solos, a erosão acelerada está relacionada a outra forma de degradação, a saber, o assoreamento. $\mathrm{O}$ aumento da quantidade de sedimentos gerados pela erosão acelerada dificulta o transporte por parte dos canais fluviais, ocasionando o assoreamento. Tal processo, além de ampliar as possibilidades de ocorrência de enchentes, representam significativa ameaça aos sistemas de abastecimento de água das cidades (QUARESMA, 2012).

\subsection{Erosão regressiva}


Além das ravinas e voçorocas, outra forma de erosão que merece destaque, tendo em vista sua ocorrência na área em estudo, trata-se da erosão regressiva de canais fluviais.

A erosão regressiva é um tipo de erosão linear ocasionada pelos rios, e que se propaga em direção às cabeceiras como tentativa de estabelecer perfis de equilíbrio. O rompimento do estado de equilíbrio dos perfis pode ocorrer pelo abaixamento do plano de água em um determinado ponto do rio que, segundo Penteado (1978), reduz o declive a jusante e a velocidade da corrente, resultando na deposição de parte da carga transportada e na elevação do leito. Nessa situação, à montante do ponto, o declive aumenta devido ao abaixamento do nível e a corrente acelera, resultando em erosão que se propagará em direção às cabeceiras. Outra situação exposta pela autora e, que poderá gerar tal processo, trata-se de movimentos tectônicos que resultem no basculamento do leito, modificando o declive, alterando todo o perfil, por deposição, se o declive diminuir, ou por erosão, se aumentar.

A relação entre a erosão regressiva e a atividade tectônica também foi observada por Guedes et al. (2006), que identificaram anomalias dos perfis longitudinais de canais fluviais da bacia do Rio Santo Anastácio (SP) em relação às curvas de melhor ajuste, indicando a subsidência do baixo curso e ascensão do alto curso. Os autores consideraram tais anomalias como consequências de alteração de nível de base local devido à ação neotectônica.

A erosão regressiva depende do gradiente do canal, o qual pode ser estabelecido pela divisão da altura do leito em relação ao nível de base pelo comprimento do canal fluvial. Assim, quanto maior o gradiente, maior será a força de recuo exercida pelo rio.

Tal processo poderá dificultar a delimitação de determinadas bacias hidrográficas, tendo em vista que poderá causar deslocamento do divisor de águas na mesma direção dos recuos mais intensos, resultando em divisores não coincidentes com a linha geral de cumeada.

A erosão regressiva também está relacionada às capturas fluviais. Tendo em vista que a escavação dos vales pelos rios, na busca pelo estabelecimento de seus perfis de equilíbrio, se processa por regressão, ou seja, da foz em direção às cabeceiras. O curso d'água que recuar de forma mais intensa poderá capturar outro posicionado no lado oposto da vertente, cuja força de recuo foi inibida pela menor declividade (PENTEADO, 1978).

Assim, a captura fluvial pode ser entendida como o desvio das águas de uma bacia hidrográfica para outra, resultando na ampliação de uma rede de drenagem em detrimento de sua vizinha.

Em relação ainda ao problema da erosão remontante, cabe destacar as contribuições de Quaresma (2012), o qual observou o fenômeno da erosão regressiva em diversos canais de primeira ordem pertencentes à 
bacia do Rio Santo Anastácio. Para o autor, os processos acelerados verificados foram originados pela ação conjunta de fragilidades ambientais e da intensidade do uso e ocupação da terra por parte da sociedade.

\subsection{Equilíbrio dinâmico, perfil de equilíbrio e nível de base}

Os rios, as redes de drenagem e as bacias hidrográficas representam diferentes níveis escalares de sistemas abertos, e deste modo, trocam matéria e energia com os demais sistemas componentes do seu universo (QUARESMA, 2012).

Com base na Teoria do Equilíbrio Dinâmico, é possível afirmar que tais sistemas buscam o estado de equilíbrio, quando os processos aluviais refletem o balanceamento entre o input e output de matéria e energia, manifestando-se não somente nos processos, mas também por meio das formas do perfil longitudinal (CHRISTOFOLETTI, 1980).

A aplicação dessa abordagem no estudo de perfis longitudinais de canais fluviais resultou no conceito de perfil de equilíbrio ou perfil estacionário, no qual, as forças opostas da erosão e da resistência se cancelam e se ajustam, e o input e o output de matéria e energia são equacionados pelo ajustamento das formas dos canais fluviais.

Assim, um rio terá atingido o equilíbrio dinâmico quando seu perfil longitudinal expressar ajustamento entre as variáveis componentes, resultando em um equacionamento entre a importação e a exportação de energia e matéria, bem como na realização de mesmo trabalho em todas as suas partes (CHRISTOFOLETTI, 1981).

Para Penteado (1978), o perfil de equilíbrio trata-se do perfil exatamente necessário ao transporte do material fornecido ao rio. Neste caso, estabelece-se uma inclinação tal que a corrente não pode cavar ou depositar, mas apenas transportar a sua carga.

Strahler e Strahler (2005) apresentam um conjunto de processos que conduzem ao estabelecimento de perfis de equilíbrio em canais fluviais. Segundo os autores, se a cada ano aumentar o acúmulo de sedimentos no canal de forma a superar a sua capacidade de transporte, a superfície do canal será levantada, resultando em aumento sequencial da declividade, velocidade do fluxo e da habilidade para carregar sedimentos. Finalmente, a declividade atingirá um ponto no qual a corrente apenas transportará os sedimentos que receber. Se houver redução na quantidade de sedimento que flui para a corrente, essa irá gradualmente erodir seu canal verticalmente, reduzindo sua declividade, bem como a sua habilidade em carregar sedimentos, até que somente possa transportar a quantidade que recebe das encostas. Assim 
que todos os canais experimentarem esse processo, todo o fluxo tende a um estado no qual as declividades de todos os seguimentos formarão uma rede coordenada que apenas carregará os sedimentos recebidos da contribuição da bacia de drenagem.

Dentre os processos que podem causar o rompimento do equilíbrio pré-existente, forçando o reajustamento da rede de drenagem, podem ser citadas as alterações no nível de base local e geral, bem como modificações no sistema hidrológico da bacia hidrográfica, sendo essas principalmente provocadas pelo uso e ocupação das terras (QUARESMA, 2012).

\section{Procedimentos Metodológicos}

O presente trabalho pode ser classificado como uma pesquisa descritiva e explicativa com base em Yin (2001), na medida em que busca descrever características de fenômenos, estabelecendo relações entre variáveis para identificar aquelas responsáveis pela sua ocorrência na área de estudo. O estudo de caso e as atividades de gabinete são apresentadas a seguir.

\section{1 Área de Estudo}

O Córrego Santa Cruzinha é um dos afluentes da margem direita do baixo curso do Rio Santo Anastácio, sendo este localizado entre as coordenadas $21^{\circ} 49^{\prime} 07^{\prime \prime}$ ' a $22^{\circ} 16^{\prime} 54^{\prime \prime}$ ' de latitude S e $51^{\circ} 24^{\prime} 27^{\prime \prime}$ a $52^{\circ} 06^{\prime} 33^{\prime \prime}$ de longitude O. A bacia do Córrego Santa Cruzinha, objeto de estudo do presente trabalho, localiza-se entre as coordenadas $21^{\circ} 49^{\prime} 38^{\prime \prime}$ e $21^{\circ} 52^{\prime} 12^{\prime \prime}$ ' de latitude $\mathrm{S}$ e $52^{\circ} 6^{\prime} 70^{\prime \prime}$ e $52^{\circ} 02^{\prime} 98^{\prime \prime}$ de longitude O.

As características das cabeceiras do referido Córrego levaram Stein (1999) a denominá-las como cabeceiras de erosão acelerada, tendo em vista sua história evolutiva. Além disso, tal autor afirma que a maior densidade de drenagem e as maiores declividades das encostas criam condições favoráveis à retomada erosiva induzida pelo homem.

\subsection{Atividades de gabinete}

\subsubsection{Levantamento Bibliográfico}

Para a pesquisa bibliográfica, foram consultadas as bases de livros, teses e dissertações das bibliotecas da Universidade Estadual de Campinas (Unicamp) e da Universidade Estadual Paulista (Unesp - Rio Claro e Presidente Prudente). Também foram consultados anais de encontros, simpósios e congressos, bem como 
trabalhos científicos em revistas, todos vinculados à temática da erosão e perda de solos, com especial atenção à região oeste do estado de São Paulo.

\subsubsection{Restituição da rede de drenagem}

Dentre os índices morfométricos existentes para se verificar a possível reativação da rede de drenagem e erosão remontante, foram selecionadas a densidade de drenagem (Dd) e a densidade hidrográfica (Dh).

Horton (1968) foi quem primeiro definiu os índices de densidade hidrográfica (Dh), a qual chamou de frequência de rios, e densidade de drenagem (Dd). O índice de frequência de rios trata da relação entre número total de rios das diversas ordens por unidade de área. Por outro lado, a densidade de drenagem estabelece a relação entre o comprimento total dos canais e a área da bacia hidrográfica, devendo-se levar em consideração os canais perenes e intermitentes. Tem por finalidade, deste modo, comparar o comprimento dos canais drenadores existentes em uma área de tamanho padrão.

No presente trabalho, preferiu-se adotar as adaptações realizadas por Rodrigues (2006), Simon (2010) e Quaresma (2012), as quais substituem o número total de rios pelo número total de canais de primeira ordem, e o valor da área da bacia pela área de uma amostra circular correspondente a $10 \mathrm{~km}^{2}$.

Essas modificações se encaixam nos objetivos do presente trabalho, tendo em vista que o aumento significativo de canais de primeira ordem reflete condições de reativação da rede de drenagem.

Para a determinação da evolução temporal da rede de drenagem, optou-se pela análise do período entre 1962 e 2010. Os procedimentos seguiram de acordo com a metodologia apontada por Nunes et al. (1995), segundo a qual, inicia-se com a montagem do mapa de drenagem a partir da utilização de bases cartográficas em escala adequada e de imagens de sensores. Os procedimentos desta etapa se resumem no detalhamento do traçado da drenagem existente nas bases cartográficas pela utilização das imagens dos referidos sensores utilizados.

Para a realização desta atividade, foram utilizadas folhas topográficas de escala 1:50.000; Equidistância das curvas de nível: 20 metros; Datum Vertical: Marégrafo Imbituba, SC; Datum horizontal: Córrego Alegre, MG. Uma vez que as mesmas não se encontravam disponíveis em arquivos vetoriais, foi necessária sua aquisição em estado analógico, procedendo à sua digitalização, georreferenciamento e vetorização. Além disso, foram adquiridas fotografias aéreas pancromáticas datadas do ano de 1962, em escala aproximada de 1:25.000, provenientes do levantamento aerofotográfico do Estado de São Paulo, realizado por Aerofoto Natividade Ltda., as quais foram obtidas junto ao Laboratório de Geoprocessamento do Instituto Agronômico de Campinas - IAC. 
A visualização do estereomodelo e a restituição da rede de drenagem de 1962 foram realizadas com auxílio de estereoscópio de bolso, e seguiu as técnicas para fotointerpretação apresentadas por Garcia (1982).

Para a restituição da rede de drenagem de 2010, foram utilizadas imagens do sensor PRISM Panchromatic Remote-sensing Instrument for Stereo Mapping do programa ALOS - Advanced Land Observing Satellite, obtidas do Instituto Brasileiro de Geografia e Estatística (IBGE).

O sensor PRISM trata-se de radiômetro pancromático, com resolução espacial de 2,5 m no nadir. Devido a três sistemas ópticos independentes com visada nadir, frontal e para trás, e ao campo de visada amplo, o sensor permite a aquisição de pares estereoscópicos com recobrimento de $35 \mathrm{~km}$ ao longo da direção de deslocamento da plataforma.

A visão estereoscópica de tais imagens foi gerada no software Arcgis 9.3, tendo sido necessária a utilização de óculos especiais (3d). Deste modo, a vetorização da rede de drenagem de 2010, realizada no interior das amostras circulares, pôde ser executada diretamente em tela.

Importante mencionar que todas as bases e vetores foram adequados ao mesmo sistema de orientação, adotando-se a Projeção Transversa de Mercator e os Datuns Vertical e Horizontal, Marégrafo de Imbituba - SC e Córrego Alegre - MG, respectivamente.

A restituição foi realizada individualmente para os anos de 1962 e de 2010. Posteriormente, realizou-se uma análise comparativa entre os dois cenários a fim de que possíveis erros pudessem ser identificados e corrigidos.

Os resultados foram tabulados no software Microsoft - Excel 2003, permitindo comparar os índices de densidade de drenagem e densidade hidrográfica entre os referidos anos.

Além da restituição da rede de drenagem, foi dada atenção às características de largura e entalhamento dos canais de primeira ordem, possibilitando a identificação de rupturas de declive ao longo dos perfis longitudinais, bem como a existência de outras formas indicadoras de retomada de erosão em ambos os períodos analisados.

Também foram observadas características referentes ao uso e ocupação das terras no interior da amostra circular analisada. 


\section{Resultados e discussões}

A análise das fotografias aéreas de 1962 permitiram observar que a área das cabeceiras do Córrego Santa Cruzinha, compreendida no interior da amostra circular adotada, já havia sofrido modificação intensa por parte do uso e ocupação pelo sistema antrópico. Tal fato se verifica pela quase inexistência de cobertura vegetal natural. Isto permite corroborar os estudos de Fonzar (1981), Stein (1999) e Quaresma (2012), os quais discutiram o acelerado processo de uso e ocupação das terras no Pontal do Paranapanema, iniciado com a colonização na década de 1920. Logo, verifica-se que, em um período de apenas 40 anos, toda a vegetação natural da área foi removida e substituída por culturas agrícolas e por pastagem (Fig. 1).
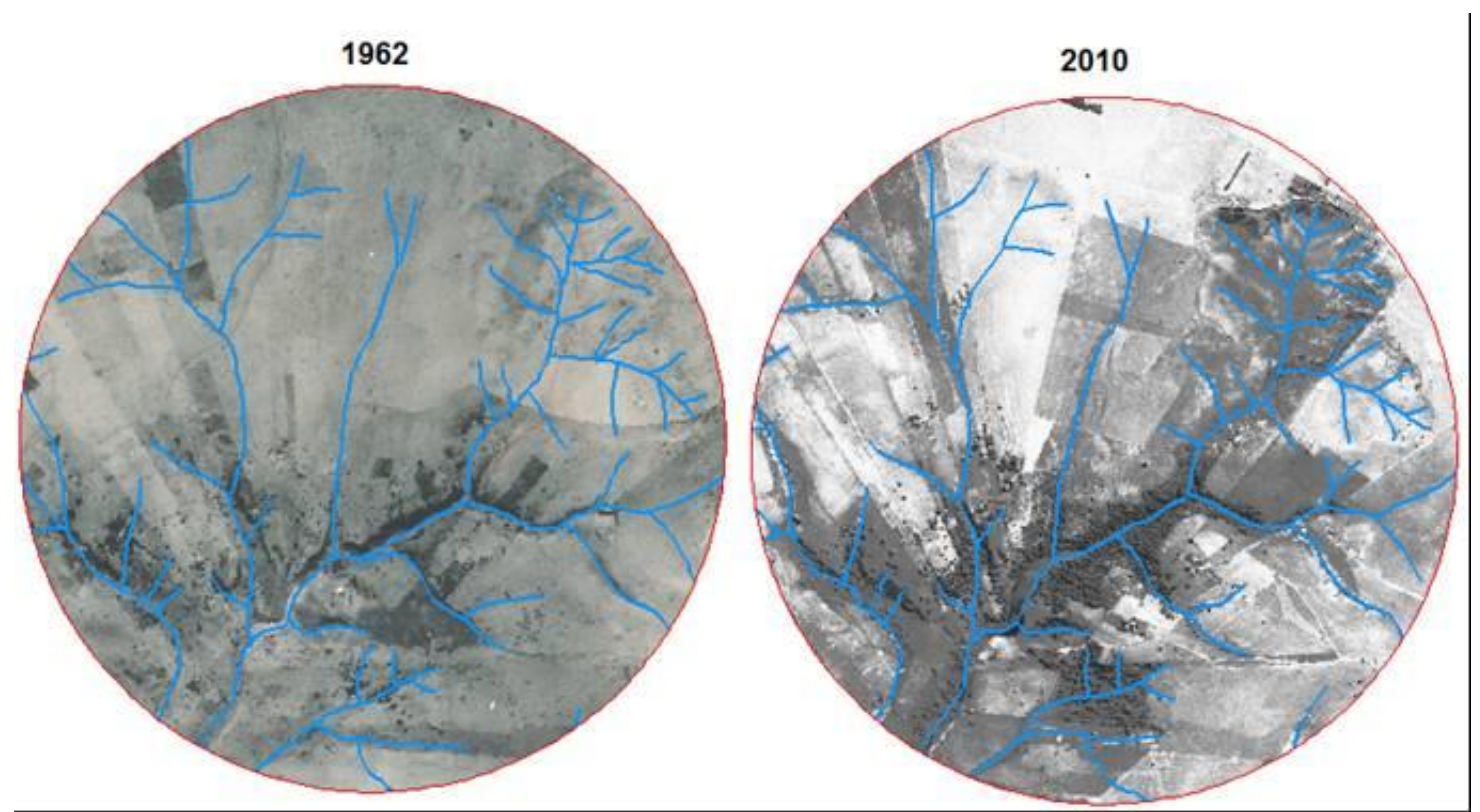

Figura 1: Interior da amostra circular com traçado da rede de drenagem - cenários de 1962 e 2010.

Fonte: Da esquerda para a direita - fotografias aéreas 5265 e 5758/1962 - IAC e imagem do satélite ALOS/Prism no 062714040 - IBGE.

A figura 1 permite verificar visualmente que, nos dois cenários, a vegetação nativa é escassa, com uma pequena melhora no quadro mais atual, embora ainda insuficiente.

O traçado da rede de drenagem nos dois anos analisados, conforme a metodologia descrita anteriormente, permitiu a elaboração da figura 2 . 


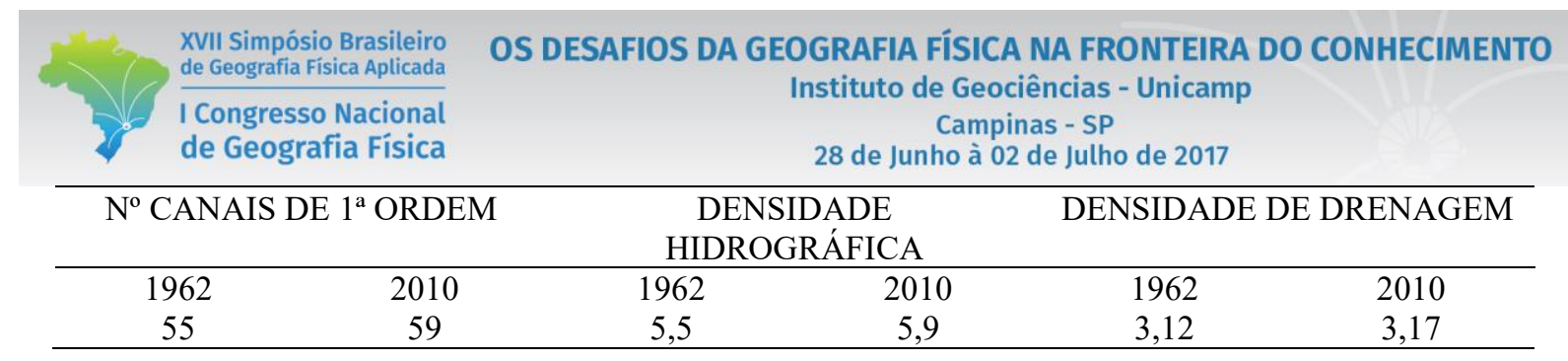

Figura 2: Número de canais de $1^{\mathrm{a}}$ ordem e valores dos índices Dd e Dh na amostra circular entre os anos de 1962 e 2010.

Fonte: Os autores.

Com base na figura 2, a comparação da rede de drenagem dos dois anos considerados permitiu verificar alterações nos canais fluviais, a saber: aumento de comprimento em 1,60\%, e surgimento de quatro novos canais de primeira ordem, representando um acréscimo de 7,27\%.

A fotointerpretação, realizada em pares estereocópicos de fotografias aéreas de 1962, permitiu verificar que a rede de drenagem se encontrava em processo de entalhamento intenso dos talvegues. Os indícios de erosão acelerada observados nos canais fluviais indicaram desestabilidade da rede de drenagem, e a busca desta pelo restabelecimento do estado de equilíbrio perdido já na década de 1960.

Verificou-se também a ocorrência de dois pequenos canais desaguando em desnível em canal de maior ordem, indicando que os mesmos não acompanharam o ritmo de entalhamento do vale principal.

Os canais de primeira ordem, os quais se destacavam no processo de entalhamento de seus antigos leitos fluviais, demonstraram nítido estado de erosão remontante, com o encaixamento dos rios se projetando da embocadura em direção às partes mais elevadas dos perfis longitudinais (Figura 3).

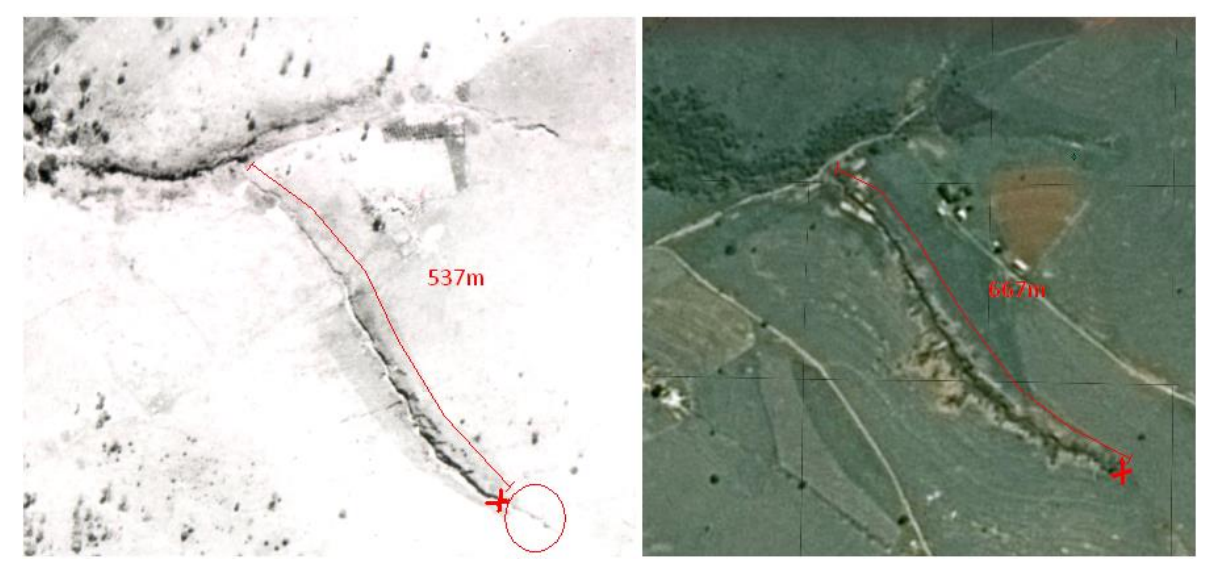

Figura 3: Recorte sobre nascentes (Leste) do Córrego Santa Cruzinha.

Fontes: fotografia aérea $\mathrm{n}^{\circ}$ 5758/1962 - IAC e imagem do satélite IKONOS/2006 - GoogleEarth.

A figura 3 refere-se a dois recortes de uma mesma área do interior da amostra circular, porém em cada um dos momentos analisados. A imagem da esquerda trata-se de fotografia aérea de $1962\left(\mathrm{n}^{\circ}\right.$ 5758) e a da direita, imagem IKONOS, datada de 14/07/2006. O processo de entalhamento do canal fluvial verificado na imagem mais atual não se trata de processo cuja gênese possa ser atribuída às causas recentes, sendo 
proveniente de erosão linear acelerada iniciada na década de 1960. Pode-se verificar que o canal no ano de 1962 encontrava-se em processo de encaixamento, formando um vale em "V", ampliando assim as declividades das vertentes. Segundo Davis (1899) Apud: Christofoletti (1980), tal processo, relacionado à fase de juventude de sua Teoria, seria seguido por desmoronamentos e ravinamentos, o que pode ser observado em ambos os recortes, porém mais nitidamente e de forma mais evoluída no que se refere ao ano de 2006. Isso permite supor que algo ocorreu no passado, rompendo o estado de equilíbrio dinâmico da rede de drenagem, resultando em reativação erosiva da mesma, com processos semelhantes ao que se verifica por ação de eventos naturais relacionados a movimentos rápidos de origem tectônica ou eustática.

Outra informação destacada pela figura 3, refere-se à evolução da erosão do talvegue que se processa entre as datas analisadas, em direção a montante, constituindo-se assim em bom exemplo da ocorrência de erosão remontante, verificada em outros canais de primeira ordem pertencentes à amostra em análise. $\mathrm{O}$ " $\mathrm{x}$ " em cor vermelha, traçado no interior da figura $3 \mathrm{em}$ ambos os cenários, refere-se a uma quebra na continuidade do perfil longitudinal do canal, formando um degrau. Como pode ser observado, este se afasta cerca de $130 \mathrm{~m}$ do ponto da embocadura no intervalo de tempo entre as datas analisadas. $\mathrm{O}$ círculo em vermelho sobre o recorte em fotografia aérea demonstra trecho do canal a montante da referida ruptura, sendo claramente mais elevado e menos profundo do que o trecho do rio intensamente escavado, conforme observado a partir da análise estereoscópica.

\section{Considerações Finais}

A perda dos solos, provocada pela ação da erosão constitui-se em um grande problema de sustentabilidade, haja vista que impacta as esferas econômica, social e ambiental. Diante desses problemas, grande ônus tem sido imputado à sociedade e ao poder público, os quais se veem obrigados a realizar grandes investimentos financeiros e em trabalho, para fins de controle e mitigação dos processos erosivos existentes.

Isto revela a importância de estudos que visam entender a gênese e dinâmica dos processos erosivos desenvolvidos na região, especialmente para o poder público, que, em muitos casos, carece de trabalhos técnicos que auxiliam na tomada de decisões em relação ao adequado enfrentamento do problema.

Deste modo, a definição do tipo de erosão e a caracterização de sua evolução são elementos indispensáveis à escolha das práticas de conservação e recuperação adequadas ao problema. 
O presente trabalho permitiu identificar indícios de reativação da rede de drenagem por ação de erosão remontante dos canais de primeira ordem. A presença de ruptura de declive ao longo do leito do canal fluvial e o seu deslocamento em direção a montante ao longo do período analisado revelam tal processo.

O quadro de alteração do uso e ocupação das terras, com remoção quase total da cobertura vegetal natural em menos de 40 anos após o início da colonização, permite apontar a ação antrópica como o principal agente desencadeador dos processos erosivos identificados.

O quadro de degradação se agrava tendo em vista as fragilidades ambientais naturais características da área de estudo, conforme apresentadas no Referencial Teórico. Deste modo, os resultados ora apresentados não eliminam a influência de elementos naturais, tais como a neotectônica. Ao contrário, o presente trabalho permite destacar a importância de se considerar o papel da ação antrópica, materializada nas modificações do recobrimento da superfície, como elemento corresponsável e fundamental ao entendimento da gênese e aceleração dos processos erosivos identificados.

\section{Bibliografia}

CHRISTOFOLETTI, A. Geomorfologia. São Paulo: Edgard Blucher, 1980.149p.

CHRISTOFOLETTI, A. Geomorfologia Fluvial. São Paulo: Edgard Blucher, 1981.313p.

FONZAR, B. C. O processo de ocupação regional, o modelo urbano e o conforto térmico na Alta Sorocabana: um teste aplicado a Presidente Prudente. São Paulo, 1981. 156f. Dissertação (Mestrado) - FFCL/USP, 1981.

GARCIA, G. J. Sensoriamento remoto: princípios e interpretação de imagens. São Paulo: Nobel, 1982. 357p.

GUEDES, I. C. et al. Análise de perfis longitudinais de drenagens da bacia do rio Santo Anastácio (SP) para detecção de possíveis deformações neotectônicas. Revista UnG - Geociências, v. 5, n. 1, p.75-102. 2006.

GUERRA, A. J. T. O início do processo erosivo. In: GUERRA, A. J. T.; SILVA, A. S.; BOTELHO, R. G. M. (org.). Erosão e conservação dos solos: conceitos, temas e aplicações. Rio de Janeiro: Bertrand Brasil, 1999.

HORTON, R. E. Erosional development of streams and their drainage basins: hydorphysical approach to quantitative morphology. Geol. Soc. Amer. Bulletin, v.56, n. 4, p.709-717, 1968.

MARQUES, J. Q. A. Conservação dos solos no Brasil. In: CONGRESSO PAN-AMERICANO DE CONSERVAÇÃO DO SOLO, São Paulo, Anais... São Paulo, Secretaria da Agricultura, 1966.

NUNES, B. A. et al. Manual Técnico de Geomorfologia. Rio de Janeiro: IBGE, 1995. 112p.

PENTEADO, M. M. Fundamentos de geomorfologia. 2ed. Rio de Janeiro: IBGE, 1978. 180p.

QUARESMA, C. C. Reativação da rede de drenagem e processos erosivos na Bacia do Rio Santo Anastácio SP/Brasil: contribuições à geomorfologia antrópica e ao entendimento das organizações espaciais. Campinas, 2012. 256p. Tese (Doutorado em Geografia) - Universidade Estadual de Campinas - UNICAMP.

RODRIGUES, T. R. I. Influência de reservatórios hidrelétricos na gênese e evolução da rede de drenagem no baixo curso do rio São José dos Dourados (SP). Campinas, 2006. 218f. Tese (Doutorado) - FEAGRI/UNICAMP.

SIMON, A. L. H. Influência do reservatório de Barra Bonita sobre a Morfohidrografia da baixa bacia do rio Piracicaba - SP: Contribuições à Geomorfologia Antrópica. Rio Claro, 2011. 127f. Tese (Doutorado) - UNESP. 


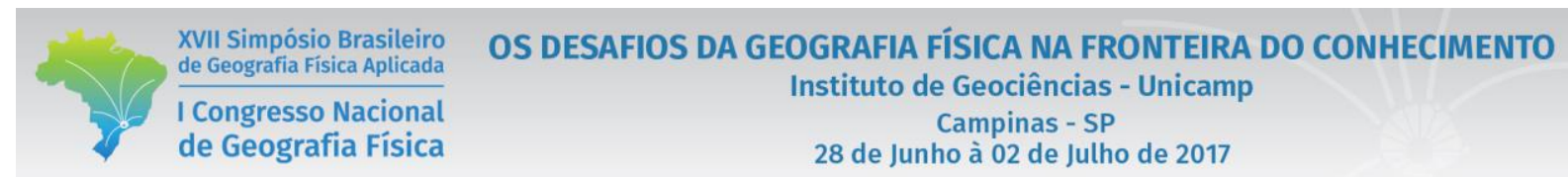

STEIN, D. P. Avaliação da degradação do meio físico Bacia do rio Santo Anastácio Oeste Paulista. Rio Claro, 1999. 197f. Tese (Doutorado em Geociências) - UNESP.

STRAHLER, A. N.; STRAHLER, A. H. Physical Geography: Science and systems of the Human Enviroment, 3 ed. New Jersey: John Wiley \& Sons. 2005. 